\title{
Glycosylated Hemoglobin Levels and Lipid Profile in Type 1 Diabetes Mellitus and Precipitating Factorsin Diabetic Ketoacidosis
}

\author{
Chilumula Monica', Saleem ${ }^{2}$ \\ ${ }^{1} \mathrm{MD}$ Paediatrics, Gandhi Medical College, Secunderabad, ${ }^{2}$ Assistant Professor, Department of Pediatrics, Gandhi Medical College, Secunderabad.
}

\section{Abstract}

Background: Type-1 Diabetes Mellitus is the most common endocrine-metabolic disorder of childhood and adolescence. The diseases has a prevalence of approximately 1 in 2500 children at age 5 years to approximately 1 in 300 children by age 18 years. A recent study from Madras suggests that diabetes in Indian children is present in a frequency of 10.5 per 1,00,000 patient years. Prevalence of childhood diabetes among urban population in India is 0.26 per 1000. Type-1 diabetes constituted nearly 90 to $100 \%$ of all children with diabetes. Objective: The objectives of this research were to study the levels of glycosylated hemoglobin and lipid profile in type 1 diabetes mellitus in children attending Gandhi Hospital Secunderabad, Telangana and to study the precipitating factors in Diabetic Ketoacidosis (DKA). Subjects and Methods: Design: This was a Cross-Sectional study. Duration: One year and six months i.e. from January 2017 to June 2018. Participants: 50 diabetic children of age less than 18 years attending Gandhi Hospital, Secunderabad, Telangana were included in the study. The diabetic cases were studied using a predesigned and pretested proforma. A detailed clinical examination was carried out with detailed anthropometric measurements and necessary lab investigations were done. Metabolic profile was assessed by investigating for blood sugar levels, glycosylated hemoglobin, and lipid profile. Rates, ratios and percentages of presentations and significance were calculated using Chi-square test. Result: 48 $\%$ cases had onset of diabetes Mellitus at 13-18 years with Male: female ratio of 1.27: 1. $20 \%$ had family history of diabetes. $16 \%$ children had normal nutrition, $20 \%$ children had grade I and grade II, 38\% had grade III and $6 \%$ children had grade IV. 54\% children had glycosylated hemoglobin level of more than $10 \%$ indicating poor glycemic control, $32 \%$ had fair control, and $14 \%$ had good glycosylated hemoglobin levels. $62 \%$ presented with fever, $40 \%$ presented with symptoms of polyuria, polydipsia and polyphagia, $37.5 \%$ presented with vomiting, 18 $\%$ children with loose stools, abdominal pain, $20 \%$ children had breathlessness, $6 \%$ presented with seizures. $88.9 \%$ were diagnosed to have diabetic ketoacidosis as their initial presentation of diabetes mellitus Causes for precipitating factors of diabetic ketoacidosis were associated infections like pneumonia (22\%) and urinary tract infection(16\%), Non availability of insulin doses (25\%), non-acceptance by child (16.66 $\%)$. Recurrent hospitalization in the patients with 5 years diabetic duration was statistically significant. Common causes being hypoglycemia $(38 \%)$ recurrent DKA (24\%), pneumonia (12\%) and urinary tract infections ( $8 \%) .23 .52 \%$ cases were non-compliant. Conclusion: More than half of the cases $(54 \%)$ had poor glycemic control. Majority presented with classical symptoms of polyuria, polydipsia, polyphagia, fever, breathlessness and diabetic ketoacidosis as clinical presentation. Causes for precipitating factors of diabetic ketoacidosis were associated infections like pneumonia and urinary tract infection, non-availability of insulin doses and non- acceptance by child.

Keywords: Type 1 Diabetes Mellitus, Children, Glycosylated Hemoglobin, Lipid Profile, Diabetic ketoacidosis, Precipitating Factors.

Corresponding Author: Dr. Saleem, Assistant Professor, Department of Pediatrics, Gandhi Medical College, Secunderabad.

Email: drsaleemmgmc@gmail.com

Received: March 2020

Accepted: March 2020

\section{Introduction}

Diabetes Mellitus has been known since antiquity. The first accurate clinical description of the disease was made by Aretaeus of Cappadocia in the second century A.D., who stated "Diabetes is a wonderful affection, not very frequent among men, being a melting down of the flesh and limbs into the urine". Thomas Willis described the sweet character of the urine in diabetes in the later part of seventeenth century. Diabetes Mellitus was thought to be a single disease entity. The concept that diabetes mellitus is not a single disease, but rather a clinical syndrome characterized by elevated fasting and / or post prandial blood glucose and development of long-term micro vascular, macro vascular and neuropathic changes is of very recent origin and stems from numerous investigations into the epidemiology, genetics, etiology, and pathogenesis of clinical diabetes state. $^{[1]}$ Diabetes Mellitus (DM) is a metabolic syndrome characterized by hyperglycemia as a cardinal biochemical feature. The major forms of diabetes are divided into those caused by deficiency of insulin secretion due to pancreatic $\beta$ - cell damage (Type-1 DM) and those that are a consequence of insulin resistance occurring at the level of skeletal muscle, liver, adipose tissue with various degrees of $\beta$-cell impairment (Type-2 DM). Type-1 DM is the most common endocrine-metabolic disorder of childhood and adolescence. The diseases have a prevalence of approximately 1 in 2500 children at age 5 years to approximately 1 in 300 children by age 18 years. Incidence 
rates vary widely by country, that as high as 30 to 40 cases per 1,00,000 children in Finland and as low as 1 in 1,00,000 in Japan and China. ${ }^{[2]}$ There is scant epidemiological data from India, but a recent study from Madras suggests that diabetes in Indian children is present in a frequency of 10.5 per 1,00,000 patient years. Prevalence of childhood diabetes among urban population in India is 0.26 per 1000 . Type- 1 diabetes constituted nearly 90 to $100 \%$ of all children with diabetes. ${ }^{[3]}$ Worldwide, the proportion of childhood and adolescent DM attributable to type $2 \mathrm{DM}$ is increasing. There is 10 fold increases in incidence of type $2 \mathrm{DM}$ between 1982 and 1994. The highest prevalence of type 2 DM in children and adolescents is reported among some American Indian tribes (Pima and First Nation Indians), approximately $20-35$ per 1000 population in the 10-19 year age group and 50 per 1000 in the $15-19$ year age group. ${ }^{[4]}$ By 2025. India due to its immense population size and high diabetes prevalence will contribute about 57 million diabetics. ${ }^{[5]}$

\section{Subjects and Methods}

Place of Study: Department of pediatrics, Gandhi Hospital, Secunderabad, Telangana.

Type of Study: This was a Cross-Sectional study.

Sample Collection: 50 diabetic children of age less than 18 years attending Gandhi Hospital, Secunderabad, Telangana were included in the study.

Sampling Methods: Consecutive sampling.

Inclusion Criteria:

1. Age less than 18 years.

2. All diabetic children [(Fasting blood sugar $>126 \mathrm{mg} / \mathrm{dl}$ ) or (Random Blood Sugar $>200 \mathrm{mg} / \mathrm{dl}$ )].

\section{Exclusion Criteria:}

All the children aged more than 18 years were excluded from the study.

Statistical Methods: Rates, ratios and percentages of presentations and significance were calculated using Chisquare test.

Ethical Approval: Approval was taken from the Institutional Ethics Committee prior to commencement of the study.

\section{Results}

Fifty children were included in our study. Youngest diabetic encountered in our study was 1 year old male child.

Table 1: Age Distribution
\begin{tabular}{|l|l|l|}
\hline Age distribution & Number & $\%$ \\
\hline 1-6 Yrs. & 7 & $14 \%$ \\
\hline -12 Yrs. & 19 & $38 \%$ \\
\hline $13-18$ Yrs. & 24 & $48 \%$ \\
\hline
\end{tabular}

[Table 1] shows Age distribution of diabetes mellitus among the study participants. Majority of the cases $(48 \%)$ had diabetes mellitus in the age group of $13-18$ years followed by $38 \%$ in 7 to 12 years, $14 \%$ in $1-6$ years.

Table 2: Sex Incidence in Type 1 diabetes mellitus

\begin{tabular}{|l|l|l|}
\hline Sex & No. of Cases & Percentage \\
\hline Male & 28 & $56 \%$ \\
\hline Female & 22 & $44 \%$ \\
\hline
\end{tabular}

[Table 2] shows the sex incidence in diabetes mellitus among the study participants. In the present study male preponderance was noted (56\%) with Male: Female ratio of 1.27:1.

Table 3: Duration of Diabetes Mellitus

\begin{tabular}{|l|l|l|}
\hline Duration & No. of Cases & Percentage \\
\hline$<1$ Year & 11 & $22 \%$ \\
\hline 1-2 Years & 09 & $18 \%$ \\
\hline 2-3 Years & 06 & $12 \%$ \\
\hline 3 - 4 Years & 10 & $20 \%$ \\
\hline 4 - Y Years & 06 & $12 \%$ \\
\hline$>5$ Years & 08 & $16 \%$ \\
\hline
\end{tabular}

[Table 3] shows duration of diabetes mellitus among the study participants. $22 \%$ had less than 1 year of diabetic duration, $18 \%$ of the cases had 1 to 2 years, $12 \%$ had 2 to 3 years and 3 to 4 years duration was seen in 3-4 years, 4-5 years duration of diabetes mellitus was seen in $12 \%$ and more than 5 years duration was seen in $16 \%$ of cases.

Table 4: Family history of Type 1 diabetes mellitus

\begin{tabular}{|l|l|l|}
\hline History & No. of Cases & Percentage \\
\hline First degree relatives & 03 & $6 \%$ \\
\hline Second degree relatives & 07 & $14 \%$ \\
\hline Total & $20 \%$ \\
\hline
\end{tabular}

[Table 4] shows family history of diabetes mellitus among the study participants. Out 50 cases only $10(20 \%)$ had family history of diabetes mellitus. $03(6 \%)$ cases had first degree relatives and remaining $07(14 \%)$ cases were second degree relatives. No incidence of diabetes in siblings was found in the present study

Table 5: Consanguinity in Type 1 diabetes mellitus

\begin{tabular}{|l|l|l|}
\hline Consanguinity & No. of Cases & Percentage \\
\hline Second degree consanguineous & 13 & $26 \%$ \\
\hline Non consanguineous & 37 & $74 \%$ \\
\hline
\end{tabular}

[Table 5] shows consanguinity in diabetes mellitus. Out of 50 cases only 13 had consanguineous family history and rest of cases (74\%) were non consanguineous.

Table 6: Clinical profile

\begin{tabular}{|l|l|l|}
\hline Clinical profile & No. of Cases & Percentage \\
\hline Fever & 31 & $62 \%$ \\
\hline Polyuria, polyphagia and polydipsia & 20 & $40 \%$ \\
\hline Vomiting & 15 & $37.5 \%$ \\
\hline Abdominal pain & 09 & $18 \%$ \\
\hline Breathlessness & 10 & $20 \%$ \\
\hline Loose stools & 09 & $18 \%$ \\
\hline
\end{tabular}




\section{Manica \& Saleem; Glycasylated Hemaglabin Levels and Lipid Profile in Type 1 Dialetes Mellitus}

\begin{tabular}{|l|l|l|}
\hline Drowsiness & 07 & $14 \%$ \\
\hline Coma & 02 & $4 \%$ \\
\hline Seizures & 03 & $6 \%$ \\
\hline
\end{tabular}

The clinical profile in the present study is classical symptoms of polyuria and polydipsia (40 \%), Drowsiness(14\%), Fever (62\%), Vomiting's (37.5\%), Pain abdomen (18\%), breathlessness (20\%), Coma (4\%) and Seizures $(6 \%)$

\begin{tabular}{l|l|l|}
\hline Table 7: Infections Associated \\
\hline Infections & No. of Cases & Percentage \\
\hline Urinary tract infection & 08 & $16 \%$ \\
\hline Pneumonia & 11 & $22 \%$ \\
\hline Candidiasis & 02 & $4 \%$ \\
\hline Skin infection & 03 & $6 \%$ \\
\hline Sepsis & 02 & $4 \%$ \\
\hline
\end{tabular}

The associated infections in the present study are pneumonia (22\%), urinary tract infections $(16 \%)$, candidiasis $(4 \%)$ skin infection $(6 \%)$, and sepsis $(4 \%)$. One female child had thyroid swelling but her thyroid profile was normal so labeled as pubertal goiter.

Table 8: Precipitating factors of DKA

\begin{tabular}{|l|l|l|}
\hline Precipitating factors of DKA & $\begin{array}{l}\text { No. of } \\
\text { Cases }\end{array}$ & Percentage \\
\hline Due to intercurrent infection & 07 & $58.33 \%$ \\
\hline $\begin{array}{l}\text { Due to non-availability of insulin (because } \\
\text { of financial restraint) }\end{array}$ & 03 & $25 \%$ \\
\hline Non acceptance by the Child & 02 & $16.66 \%$ \\
\hline
\end{tabular}

The precipitating factors of diabetic ketoacidosis were due to intercurrent infections, child refusal and non-availability of insulin due to financial constraint. There was no incidence of parental negligence of the child's conditions.

\begin{tabular}{l|l|l|}
\hline Table 9: Recurrent Hospitalizations \\
\hline Other problems & No. of Cases & Percentage \\
\hline Recurrent hospitalization & 24 & $48 \%$ \\
\hline Hypoglycemic episodes & 19 & $38 \%$ \\
\hline Recurrent diabetic ketoacidosis & 12 & $24 \%$ \\
\hline Pneumonia & 06 & $12 \%$ \\
\hline Urinary tract infection & 04 & $8 \%$ \\
\hline
\end{tabular}

In the present study we noted $48 \%$ got admitted more than once. Causes for recurrent hospitalization were hypoglycemia (38\%), diabetic ketoacidosis (24\%) and pneumonia $(12 \%)$, urinary tract infections $(8 \%)$.

\begin{tabular}{|l|l|l|}
\hline Table 10: HBA1C levels in the study \\
\hline HBA1C levels & No. of Cases & Percentage \\
\hline$<6.0 \%$ & 00 & $00.00 \%$ \\
\hline$(6.5-7.5 \%)$ & 07 & $14 \%$ \\
\hline$(7.6-10 \%)$ & 16 & $32 \%$ \\
\hline$>10 \%)$ & 27 & $54 \%$ \\
\hline
\end{tabular}

$54 \%$ of diabetic children have shown poor control, $32 \%$ had fair control, $14 \%$ had good glycosylated hemoglobin levels.

\section{Table 11: lipid profile}

\begin{tabular}{|l|l|l|}
\hline Serum Triglycerides Levels & No. of Cases & Percentage \\
\hline$<150$ & 37 & $74 \%$ \\
\hline $150-200$ & 08 & $16 \%$ \\
\hline$>200$ & 00 & $00 \%$ \\
\hline
\end{tabular}

In the present study lipid profile of all the children was analyzed by their serum cholesterol and triglycerides. No child had hypercholesterolemia (> $200 \mathrm{mg} / \mathrm{dL}$ ). $74 \%$ children had triglyceride levels below $150 \mathrm{mg} / \mathrm{dL}, 16 \%$ were in the range of $150-199$ and no child had high level of triglycerides

\section{$\underline{\text { Tests of Statistical Significance }}$}

Table 12: Age at presentation and glycemic control P-value: 0.18

\begin{tabular}{|l|l|l|l|}
\hline $\begin{array}{l}\text { Age at } \\
\text { presentation }\end{array}$ & Good control & Poor control & Total \\
\hline$<9 \mathrm{yrs}$. & 07 & 04 & 11 \\
\hline$>9 \mathrm{yrs}$. & 16 & 23 & 39 \\
\hline
\end{tabular}

Table 13: Sex distribution and glycemic control $P$-value $=0.0052$

\begin{tabular}{|l|l|l|l|}
\hline $\begin{array}{l}\text { Sex } \\
\text { distribution }\end{array}$ & Good control & Poor control & Total \\
\hline Female & 15 & 07 & 22 \\
\hline Male & 08 & 20 & 28 \\
\hline Total & 23 & 27 & 50 \\
\hline
\end{tabular}

Table 14: Duration of diabetes and Glycemic control P value $=0.19$

\begin{tabular}{|l|l|l|l|}
\hline $\begin{array}{l}\text { Duration of } \\
\text { diabetes }\end{array}$ & Good control & Poor control & $\begin{array}{l}\text { Total } \\
\text { Number }\end{array}$ \\
\hline$<5$ years & 21 & 21 & 42 \\
\hline$>5$ years & 02 & 06 & 08 \\
\hline Total & 23 & 27 & 50 \\
\hline
\end{tabular}

Table 15: DKA and Glycemic control $\quad$ P-value $=0.109$

\begin{tabular}{|l|ll|l|l|l|}
\hline \multicolumn{2}{|c|}{} & \multicolumn{2}{|c|}{ Glycemic control } & \multirow{2}{*}{ Total } \\
\cline { 3 - 6 } \multicolumn{2}{|c|}{} & Good & Poor & \\
\hline \multirow{2}{*}{ DKA } & Absent & Number & $12(24 \%)$ & $26(52 \%)$ & 38 \\
\cline { 2 - 5 } & Present & Number & $1(2 \%)$ & $11(22 \%)$ & 12 \\
\cline { 2 - 5 } & Number & 13 & 37 & 50 \\
\hline
\end{tabular}

Table 16: Recurrent hospitalizations in type1 diabetes mellitus $\mathbf{P}$-value $=\mathbf{0 . 0 1}$

\begin{tabular}{|l|l|l|l|}
\hline $\begin{array}{l}\text { Recurrent } \\
\text { hospitalizations }\end{array}$ & $\begin{array}{l}<\mathbf{5} \text { years of } \\
\text { duration }\end{array}$ & $\begin{array}{l}\text { >5 years of } \\
\text { duration }\end{array}$ & Total \\
\hline Present & 17 & 07 & 24 \\
\hline Absent & 25 & 01 & 26 \\
\hline Total & 42 & 08 & 50 \\
\hline
\end{tabular}

\section{Discussion}

Diabetes Mellitus is one of the chronic diseases of children and youth worldwide. Very little is known about the magnitude or determinants of childhood and youth onset diabetes in India. The primary objective of the study was to analyze the HbA1C levels, lipid profile in type 1 diabetes mellitus in children and precipitating factors in diabetic ketoacidosis. This study included 50 children with type 1 diabetes mellitus. In the present study peak incidence was in 
age group of $13-18$ years (48\%). Male predominance was encountered with male to female ratio 1.27:1. In a similar study peak age at diagnosis was 11 years in girls and between 11 to 18 years in boys and female predominance was present. ${ }^{[6]}$ Age was found to be significant factor of glycemic control. Patients with poor glycemic had higher mean of age 12 than the group with good glycemic control. Vanelli et al, ${ }^{[7]}$ who studied children and adolescents with diabetes and found that increasing age was associated with a higher mean $\mathrm{HbA1c}$. It was noticed in this study that males (40\%) had poor glycemic control when compared to females whereas female patients aged $>12$ years had poor glycemic control than males of the same age group in the result that has been recorded by Setoodeh et al ${ }^{\left[{ }^{[8]}\right.}$ In the present study, $42 \%$ of the children in the group with duration of disease < 5 years had a good glycemic control and $12 \%$ had poor control with duration of disease $>5$ years. In the present study $20 \%$ had family history of diabetes mellitus. $6 \%$ had first degree diabetic relatives and $14 \%$ had second degree relatives. $26 \%$ children had second degree consanguineous family history. A similar study conducted at Chennai showed $6.14 \%$ incidence of diabetes in the siblings and $20.52 \%$ of second-degree consanguineous family history. ${ }^{[9]}$ Out of 50 study participants $16 \%$ had normal nutrition, 20 $\%$ had Grade I and Grade II, $38 \%$ had Grade III and $6 \%$ had Grade IV malnutrition as per IAP Grades. 8 children had normal nutrition. The above findings were corroborated with a study which showed $24.36 \%$ had normal nutrition, $20.50 \%$ had grade I, $29.48 \%$ had grade II, $21.79 \%$ had grade III and $3.84 \%$ had grade IV malnourishment. ${ }^{[9]}$

In the present study $24 \%$ were diagnosed to have diabetic ketoacidosis as their cause of admission. The clinical manifestations of diabetic ketoacidosis were classic symptoms of polyuria, polydipsia with breathlessness (20\%), vomiting's $(37.5 \%)$, abdominal pain (18\%), drowsiness (14\%), comatose (4\%) and convulsions (6\%). Different studies have mentioned higher incidence of diabetic ketoacidosis in $77 \%$ (Likitmaskul Set al), ${ }^{[6]} 69 \%$ (Poovazhagi $\mathrm{V}$ et al) ${ }^{[9]}$ and $79 \%$ (Pinkey JH et al), ${ }^{[10]}$ as initial presentation. HBA1C level in the present study showed $54 \%$ to be of poor glycemic control, $32 \%$ fair control and $14 \%$ had good control. Two different studies showed 50\% (Poovazhagi V et al), ${ }^{[9]}$ and 28\% (Soliman et al), ${ }^{[11]}$ poor glycemic control respectively. In the present study recurrent hospitalization noted in diabetic children with duration of less than five years is $1.69 \pm 0.89$ and more than five years is $1.87 \pm 1.12$ which is statistically significant $(\mathrm{P}=0.01)$.

Recurrent hospitalization (48.00\%) was noted. Causes for recurrent admissions were hypoglycemia (38\%), recurrent $\operatorname{DKA}(24 \%)$, pneumonia(12\%) and Urinary tract infections (8\%). $38 \%$ of hypoglycemic episodes were experienced in diabetics of more than 1 year of duration in the present study. Similar findings were reported. ${ }^{[12]}$ In the present study, precipitating factors of diabetic ketoacidosis were intercurrent infection $(58.33 \%)$ non availability of insulin because of financial constraints ( $25 \%$ ), and non-acceptance of child $(16.66 \%)$. No incidence of parental negligence of child was noted in our study. The children of the parents who were illiterate were more non-compliant with the treatment. In literate parents also few children were noncompliant. Educational status of the parents is associated with the compliance of treatment and overall glycemic control. ${ }^{[13]}$

In the present study lipid profile of all the children was analyzed by their serum cholesterol and triglycerides. No child had hypercholesterolemia (> $200 \mathrm{mg} / \mathrm{dL}$ ) or high levels of triglycerides (>200 mg/dL). These findings were similar with the lipid profile of the study at Chennai.9 Increased levels of cholesterol and triglycerides are more commonly associated with Type 2 diabetes mellitus. ${ }^{[14]}$

\section{Conclusion}

More than half of the cases(54\%) had poor glycemic control. Majority presented with classical symptoms of polyuria, polydipsia, polyphagia, fever, breathlessness and diabetic ketoacidosis as clinical presentation. Causes for precipitating factors of diabetic ketoacidosis were associated infections like pneumonia and urinary tract infection, nonavailability of insulin doses and non- acceptance by child.

\section{References}

1. Lebovitz HE. Etiology and pathogenesis of Diabetes Mellitus. Pediatrics Clinics of North America 1984; 31(3):521-30.

2. Nelson WE, Behrman RF. Kliegman RM. Arvin AM. Nelson"s Textbook of pediatrics: Diabetes Mellitus. 17th Ed. USA: W. B. Saunders Company; 2004.

3. Ramachandran A, Snehalatha C, Krishnaswamy CV. Incidence of IDDM in children in urban population in southern India. Madras IDDM Registry Group Madras, South India. Diabetes Res ClinPract 1996 Oct; 34(2): 79- 82.

4. Bhatia V. IAP National Task Force for Childhood Prevention of Adult Diseases: Insulin Resistance and Type 2 Diabetes Mellitus in Childhood. Indian Pediatrics 2004; 41:443-57.

5. King H, Aulart RE, Herman WH, Global burden of diabetes 19952025: Diabetes care 1998, $21: 1414-31$.

6. Likitmaskul S, Angsusingha $\mathrm{K}$, Morris $\mathrm{S}$, Kiattisakthavee $\mathrm{P}$, Chaichanwatanakul K, Tuchinda C. Type 1 diabetes in Thai children aged 0-14 years. J Med Assoc Thai 1999 Aug; 82(8):826-32.

7. Vanelli $\mathrm{M}$ et al. Nationwide cross sectional survey of 3560 children and adolescents with Diabetes in Italy. J. Endocrinol Invest 2005; 28:692-9

8. SetoodehA et al. Female sex as a risk factor for glycemic control and complications in Iranian patients with type one diabetes mellitus. Iran J Pediat 2011; 21:373-8.

9. Poovazhagi V, Thangavelu S, Parivadini S, Ramadevi P. Clinical profile of childhood diabetes Mellitus from a tertiary care hospital in Chennai. Proceedings of 41st National Conference of the Indian Academy of Pediatrics: 2004 Jan 8th - 11thChennai.

10. Pinkey JH, Bingley PJ, Cawtell PA, Dungen DB, Gale EA. Presentation and progress of childhood diabetes mellitus: A prospective population-based study. The Bart"s Oxford study group. Diabetologia 1994 Jan; 31(1):70-4

11. Soliman AT, al Salmi, Asfour M. Mode of presentation and progress of childhood diabetes in Sultanate of Oman. J. Trop Pediatr 1997; 


\section{Manica \& Saleem; Glycasylated Hemaglabin Leuels and Lipid Prafile in Type 1 Dialetes Mellitus}

43(3):128- 32

12. Karp MM. Hypoglycemia in diabetic children and adolescence. Indian J Pediatr 1989 Nov-Dec; 56 (Suppl) 1:S93-8.

13. Danne T, Mortensen HB, Hougaard P, Lynggard H, Aanstoot H, Chiarelli $\mathrm{F}$ et al. Persistent differences among centres over 3 years in glycemic control and hypoglycemia in a study of 3,805 children and adolescents with type 1 diabetes from the Hvidore study group Diabetes Care 2001; 24: 1342-7

14. Burant CF. Medical Management of Type 2 Diabetes: Diagnosis and classification. 5th Ed. Bangalore: Panther Publishers Private Limited; 2004

Copyright: () the author(s), 2020. It is an open-access article distributed under the terms of the Creative Commons Attribution License (CC BY 4.0), which permits authors to retain ownership of the copyright for their content, and allow anyone to download, reuse, reprint, modify, distribute and/or copy the content as long as the original authors and source are cited.

How to cite this article: Monica C, Saleem. Glycosylated Hemoglobin Levels and Lipid Profile in Type 1 Diabetes Mellitus and Precipitating Factors in Diabetic Ketoacidosis. Asian J.Clin.Pediatr.Neonatol.2020;8(1):47-51.

DOI: dx.doi.org/10.47009/ajcpn.2020.8.1.12

Source of Support: Nil, Conflict of Interest: None declared. 